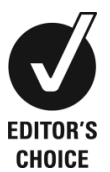

CHOICE

\title{
A multidisciplinary approach to the management of traumatic intrusion in immature permanent teeth
}

\author{
Pritika Rai, Ramesh Kumar Pandey, Richa Khanna
}

Department of Paediatric and Preventive Dentistry, Faculty of Dental Sciences, King George's Medical University, Lucknow, Uttar Pradesh, India

\section{Correspondence to Dr Pritika Rai, pritika.rai87@gmail.com}

Accepted 3 February 2016
CrossMark

To cite: Rai P, Pandey RK, Khanna R. BMJ Case Rep Published online: [please include Day Month Year] doi:10.1136/bcr-2014208571

\section{SUMMARY}

Intrusion in a developing permanent tooth is an extremely complicated traumatic injury and is rarely seen in the permanent dentition. The damage caused by the trauma to the surrounding tooth structures results in a multitude of complications during the healing process. Careful repositioning of the intruded tooth by orthodontic means, revascularisation of the immature tooth to regain vitality, and periodontal treatment to provide the most acceptable aesthetic outcome are described in this case report. It outlines the treatment options to overcome the complications and variable outcomes. The present report emphasises the importance of a multidisciplinary approach to provide complete rehabilitation of a traumatically intruded developing tooth.

\section{BACKGROUND}

Intrusion defined as the axial dislodgment of a tooth into its socket, is considered one of the most severe types of dental trauma, and leads to crushing of periodontal ligament (PDL) fibres, the neurovascular bundle and alveolar bone. Intrusive luxation in the permanent dentition is an uncommon event, constituting only $2 \%$ of injuries, and is more common in the primary dentition. ${ }^{1}$ The nature of the injury is such that it damages all soft and some hard tissue components, causing a multitude of complications. The large amount of energy required to drive the tooth into the socket damages numerous surrounding structures. Shearing stress severs the gingival fibres, compressive forces in the infrabony part of the PDL compress and severe it, and comminution of alveolar bone is evident. Tissues in the apical foramen area are damaged, especially in an open apex, and the crown covered with plaque is displaced into the damaged periodontium increasing the risk of infection. ${ }^{2}$

A multidisciplinary approach is needed to treat such injuries. The pathological outcomes needing management may include radicular inflammatory resorption (external or internal), partial or total pulp canal obliteration, dento-alveolar ankylosis, marginal bone loss and gingival recession. Pulpal necrosis and disturbance of the continued development of the root is commonly seen in immature teeth. ${ }^{3}$ The treatment options may include observation for spontaneous eruption (passive repositioning), surgical crown uncovering, orthodontic extrusion (active repositioning) or surgical extrusion (immediate repositioning).

\section{CASE PRESENTATION}

A healthy 7-year-old male patient presented with a history of a fall the previous day. The maxillary right central and right lateral incisors were observed to be intruded (figure 1). No previous dental trauma was reported and there was no history of neurological complications. The medical history was non-contributory. Extra-oral findings revealed enlarged bilateral submandibular glands.

\section{INVESTIGATIONS}

Intraoral findings: The patient presented with early mixed dentition with a normal overjet and an Angle's Class I molar relationship. Marginal gingiva around teeth 11 and 12 were red and swollen due to the associated injury. Teeth 11,12 and 21 were sensitive to percussion. Tooth 11 was severely intruded (the distance from incisal edge of tooth 11 to that of tooth 21 was $7 \mathrm{~mm}$ ) and firmly lodged into the socket. Tooth 12 was around $4 \mathrm{~mm}$ intruded compared to the level of tooth 21 intra-orally.

Radiographic examination: Extra-oral radiographic examination with the help of a lateral radiograph and an orthopantomogram (figure 2) ruled out alveolar bone fracture and penetration of the root apex though the labial bone plate or the floor of the nose. Periapical radiographs showed incomplete and wide open apices in teeth 11,12 and 21. The dentinal walls of the affected teeth were thin and incompletely formed (figure 2). There was no evidence of crown or root fracture on the radiograph. A final diagnosis of severe intrusion of tooth 11 and moderate intrusion of tooth 12 was therefore made. Tooth 21 was concussed.

\section{TREATMENT}

Immediate care: Oral hygiene instructions were given to the patient. The patient was advised to apply mouth rinses twice daily using a $0.1 \%$ chlorhexidine mouthwash and follow a soft diet for a week.

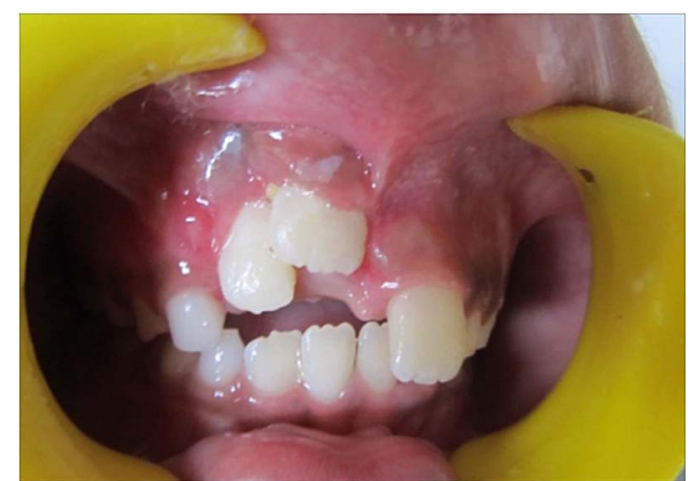

Figure 1 Clinical presentation of the intruded teeth. 

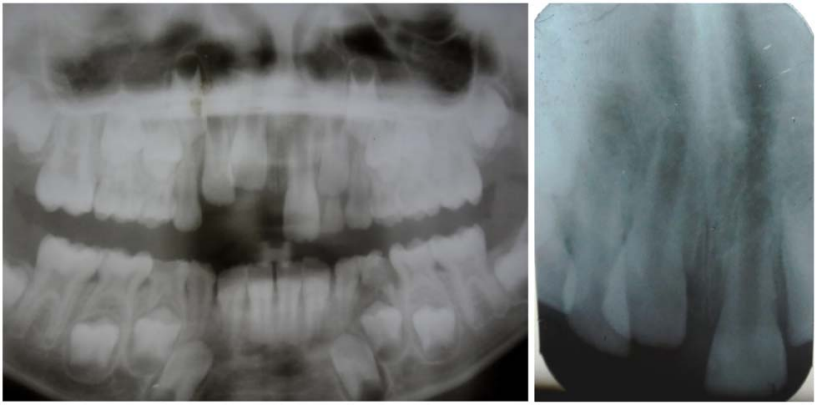

Figure 2 Preoperative radiographs showing intrusion of teeth 11 and 12.

Observation for spontaneous re-eruption followed by orthodontic extrusion: Intruded teeth were kept under observation for signs of spontaneous re-eruption without intervention. After 3 weeks of observation, tooth 12 re-erupted, but tooth 11 showed no signs of eruption. Therefore, orthodontic extrusion was initiated for tooth 11 using MBT brackets. Elastics were used to apply the slow continuous force needed in the required direction (figure 3).

Endodontic management: Ten days after initiation of orthodontic extrusion, endodontic treatment was planned. The high probability of pulpal necrosis due to the severity of the trauma necessitated endodontic treatment to prevent infection or resorption due to the presence of necrotic pulp. Revascularisation was attempted in the involved tooth instead of the conventional calcium hydroxide apexification procedure due to the presence of immature roots and thin dentinal walls. Access to the tooth lingually was now possible since the tooth had extruded from its initial position. The first step was to standardise the radiographs taken by using the same angulation and the same radiograph position at each follow-up visit using film holders (Dentsply XCP RINN) for the paralleling technique.

A local anaesthetic and a rubber dam were used while the access cavity was being prepared. Copious irrigation with 5\% sodium hypochlorite $(\mathrm{NaOCl})$ was applied along with normal saline. The canals were not instrumented in order to avoid the formation of a smear layer that can affect the dentinal walls. This is important because it is believed that intact dentinal walls play a role in signalling postnatal mesenchymal stem cells via endogenous growth factor proteins embedded in the walls. A triple antibiotic paste was prepared using ciprofloxacin powder $(500 \mathrm{mg})$, metronidazole powder $(500 \mathrm{mg})$ and minocycline powder $(100 \mathrm{mg})$ mixed with a base of propylene glycol. The prepared mixture was then inserted in the canal and temporarily obturated with glass ionomer cement.

Five weeks after the initiation of orthodontic extrusion, the tooth reached its original position in complete alignment with the other incisors (figure 3). Revascularisation of the tooth was then initiated, assuming that complete sterilisation of the canal had been achieved by the triple antibiotic paste previously inserted. The canal was reopened and irrigated with $\mathrm{NaOCl}$ and saline. Sterile paper points were used to dry the coronal half of the canal. A sterile file was then inserted and pushed beyond the apex to provoke bleeding into the canal. Once the blood reached the cemento-enamel junction (CEJ), a wet sterile cotton ball was placed on it and left untouched for $15 \mathrm{~min}$, until the formation of a clot. White mineral trioxide aggregate (MTA) was then condensed gently on the clot and a plug of about 2$3 \mathrm{~mm}$ was formed. The MTA was covered with a wet cotton pellet followed by temporary restoration to allow it to set completely. It was later replaced with a glass ionomer base and a composite restoration. The next follow-up visits were scheduled for $1,3,6,9$ and 12 months. A retention period of 12 weeks followed orthodontic repositioning. However, a relapse occurred even after this prolonged retention time, stressing the importance of a long retention phase in cases with severe intrusion due to the extensive bone loss that occurs around the involved tooth (figure 4).

Gingival tissue management: A visible gingival lag or recession was observed in the involved tooth after completion of the orthodontic treatment even though adequate oral hygiene was maintained by the patient. A high frenal attachment was observed which was suggested to be a possible cause of the gingival recession. A frenectomy and vestibuloplasty were performed to remove the obstacle (figure 4). Following soft tissue healing, the relapsed tooth was moved to its corrected position (figure 5). Improvements in gingival conditions and aesthetics were observed during 6 weeks of prolonged retention with meticulous oral hygiene by the patient (figures 6 and 7).

\section{OUTCOME AND FOLLOW-UP}

The radiographs recorded at follow-up visits up to 12 months revealed hard tissue deposition on the canal walls of the immature permanent incisor. The root did not continue to develop particularly in length, but the root apex showed deposition of hard tissue making the root apex blunt and almost closed (figure 8).

Tooth 11 displayed a slight positive response to vitality testing (pulp oximeter) after 12 months, and it was advised that it be kept under observation to check that revascularisation was successful. Heat and cold sensitivity tests and electric pulp testing (EPT) showed negative results, indicating that nerve regeneration had not occurred. However, intervention in the form of root canal treatment would only be required if clinical or radiographic signs of infection were seen in the tooth. The greyish discolouration and translucency of the tooth did not improve, creating an aesthetic problem which would require intervention in the future.
Figure 3 Orthodontic extrusion of tooth 11 .
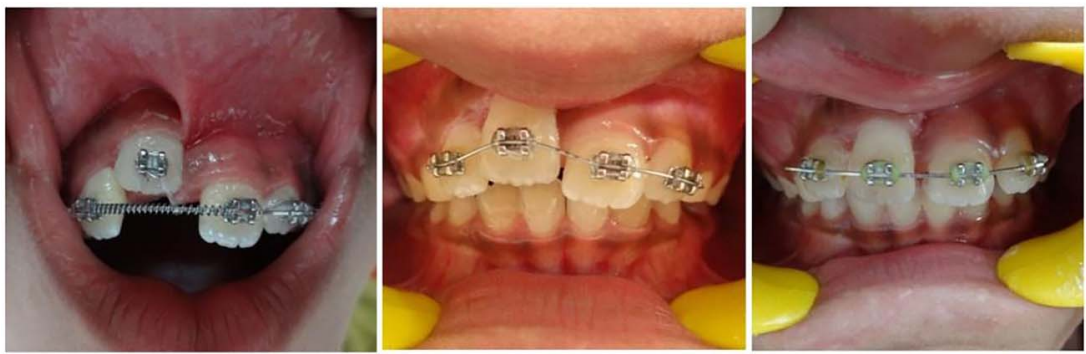
Figure 4 Gingival management and orthodontic correction of the relapsed tooth.
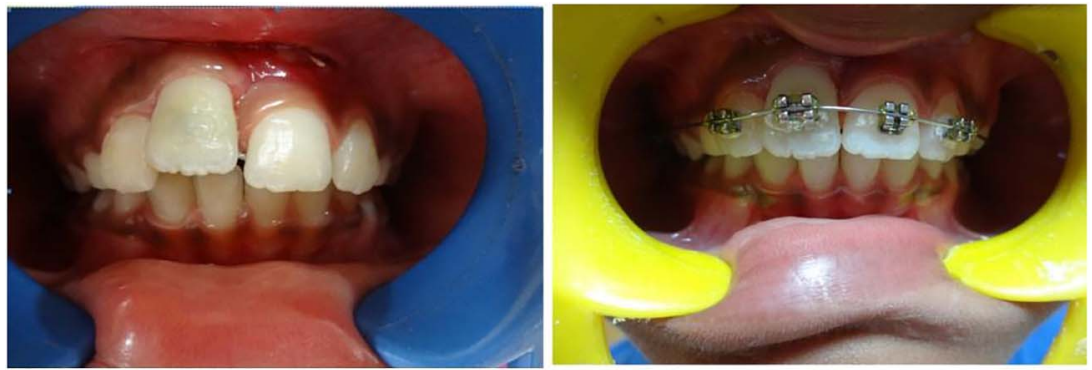

Tooth 12 showed complete apical closure with a positive response to vitality testing, indicating successful recovery from the trauma.

Frenectomy and vestibuloplasty on tooth 11 improved the gingival contour but a slight recession was still observed due to the marginal bone loss around the involved tooth.

\section{DISCUSSION}

Intrusion is the most severe form of tooth injury due to the damage it causes to surrounding structures during the traumatic displacement of the tooth into the bone. Healing is complicated by damage to the gingival attachment, contusion of the PDL and bone, and injury to Hertwig's epithelial root sheath (HERS) (mainly in immature teeth). The treatment of choice is to allow for spontaneous re-eruption, especially when the tooth apex is incomplete ${ }^{45}$ or, according to the Royal College of Surgeons of England (RCSE), for cases in which the amount of intrusion is less than $3 \mathrm{~mm} .{ }^{6}$ Re-eruption occurs particularly when the dental pulp is vital, and seldom occurs when pulp necrosis is established. ${ }^{7}$ Orthodontic repositioning represents a biological procedure for teeth with such injury, in addition to allowing access to the chamber for endodontic therapy. ${ }^{8}$ There are numerous other studies on the effects of orthodontic forces used to facilitate dental extrusion, and similar results have been observed, ${ }^{9-11}$ along with the potential of this method to prevent the appearance of ankylosis. ${ }^{9} 10$ On the other hand, a few studies have also reported an increased risk of external root resorption and marginal bone loss. ${ }^{3}$

More instances of pulp necrosis are encountered with intrusions compared other luxation injuries. Andreasen ${ }^{12}$ observed $100 \%$ pulp necrosis in intruded teeth with open apices and $62.5 \%$ in teeth with incomplete root formation. Tronstad et al ${ }^{4}$ recommended endodontic treatment of intruded teeth with open apices at 1-2 weeks after the occurrence of trauma. In the

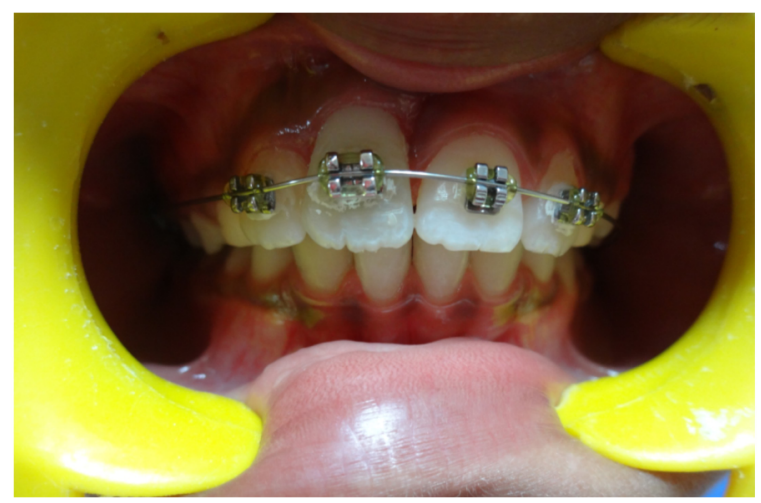

Figure 5 Orthodontic correction of the relapsed tooth after gingival healing. present case, endodontic treatment was initiated at 4 weeks after trauma, following evaluation of pulpal sensitivity using a cold spray $\left(-0^{\circ} \mathrm{C}\right)$ which showed negative results. Although no sign of active infection was present, the severity of trauma, a progressive decreased translucency revealed through transillumination, and grey colour changes in the crown indicated necrotic changes in the pulp. The traditional apexification procedure with calcium hydroxide or MTA does not strengthen the walls; indeed, calcium hydroxide can actually further weaken thin walls and leave the tooth more prone to fracture. Root wall strengthening with composite limits the possibility of root canal retreatment if the need arises in future. ${ }^{13}{ }^{14}$ Numerous case reports and series ${ }^{13-25}$ have indicated that it is possible to treat necrotic and immature permanent teeth with revascularisation procedures, leading to clinically symptom-free teeth, along with radiographic evidence of resolution of apical periodontitis. The result is a continuous increase in the thickness of dentinal walls with apical closure or further development of root length. In a similar case report, revascularisation was achieved in an immature necrotic permanent incisor after a severe intrusive luxation injury, and complete healing of the periapical area with apical closure was seen, but vitality tests after 27 weeks showed negative results indicating that revascularisation had not occurred, and root canal treatment had to be performed. ${ }^{26}$ Although there is little information about the histological features of the tissue produced in the root canal space of teeth after treatment for revascularisation, animal studies have shown that in cases of thickened walls, a cementum-like tissue was formed along the inner dentin wall (termed intracanal cementum-like tissue), and the lumen was often filled with bone-like tissue (termed intracanal bone-like tissue). ${ }^{27-29}$ However, two recent reports have described the presence of pulp-like tissue in human teeth extracted following revascularisation procedures. ${ }^{30}{ }^{31}$

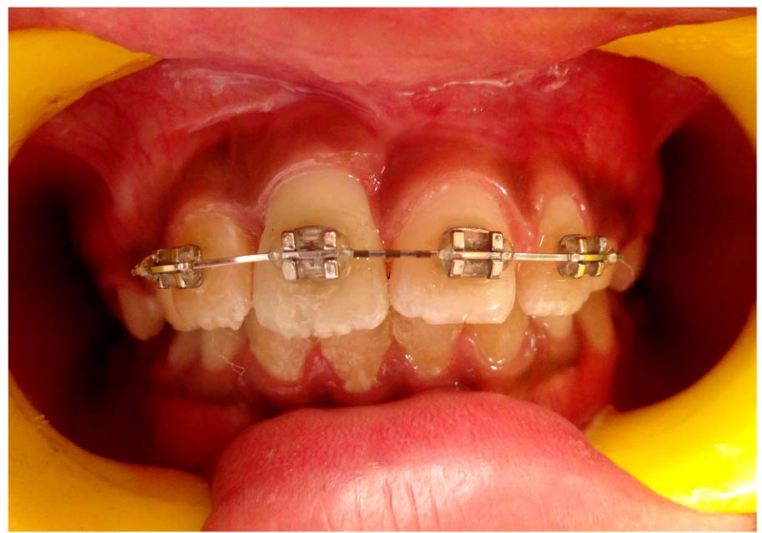

Figure 6 Final presentation of the tooth after the 6-week retention period. 


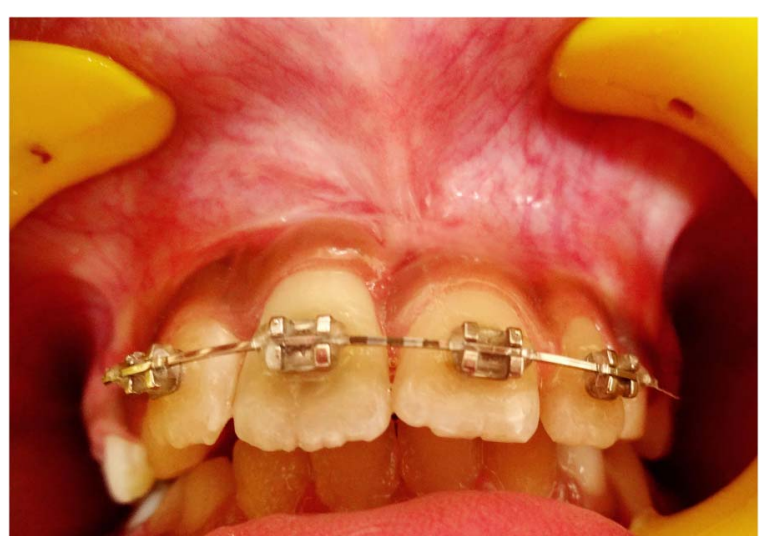

Figure 7 Improved gingival conditions with healing after soft tissue surgery.

Therefore, due to the potential maturation of the immature root along with formation of a biological barrier, a revascularisation procedure was performed in the present case. Out of the five responses to revascularisation procedures reported by Chen et $a l^{32}$ in immature permanent teeth with infected necrotic pulp tissue, the current case reports a type 2 reaction to the procedure with hard tissue deposition on the walls of the root and apex but no continuation of root formation.

A root consists of dentin and cementum which are formed from odontoblasts ${ }^{33}$ and cementoblasts ${ }^{34}$ differentiated from ectomesenchymal cells in the apical papilla and dental follicle, respectively, after they receive a signal from HERS. A functional root cannot be formed without cementum because acellular cementum and cellular cementum provide the primary and minor anchorage, respectively, of PDL fibres to the alveolar socket. $^{35}$ The viability of HERS, apical papilla and dental follicle depends on the severity of the trauma and duration of infection in immature necrotic permanent teeth. Therefore, failure of continued root development may be due to damaged HERS during intrusion.

Gingival recession is also a very common complication in cases of traumatic intrusion. Due to the associated traumatic injury, crestal bone surrounding the involved tooth is damaged. Orthodontic extrusion is usually performed slowly with the help of elastics at a rate which allows bone growth. However, any soft tissue attachments can inhibit movement of the marginal gingiva and prevent it following the normal gingival contour. Therefore, in the present case frenectomy was performed to allow the marginal gingiva to heal without stress. It has been widely believed that appropriately applied orthodontic forces do not damage the periodontium. However, it is suggested that insufficient width of attached gingiva is a predisposing factor for recession. Lang and Löe $^{36}$ concluded from their study that $2 \mathrm{~mm}$ of keratinised gingiva is adequate to maintain gingival health. Mucogingival surgery may thus be needed during orthodontic treatment to maintain sufficient width of attached gingival. ${ }^{37}$ Therefore, vestibuloplasty was also performed in this case to improve the width of attached gingiva and thus prevent recession.

Oral hygiene was also maintained satisfactorily to prevent inflammation and further disruption of the attachment. However, at 12 months after orthodontic and endodontic treatment, gingival recession of the tooth with clinical attachment loss was observed. A loss in the crestal bone level compared to the adjacent teeth was also seen and it was concluded that this had made a large contribution to the formation of the gingival defect. As the child was still growing a further correction of the gingival level was anticipated, and because the patient had a low smile line, the defect did not cause major cosmetic concern. Treatment for tooth discolouration includes conservative chemical bleaching and complete coverage restorations. The 'walking bleach technique' could be used in this case, but has the disadvantage of cervical resorption, especially in trauma cases. External bleaching could be performed either at home or in the clinic which would require several visits to the dental office. Treatment options such as veneers and porcelain crowns can also be used for aesthetic improvement. ${ }^{38}$

\section{Patient's perspective}

According to the father, the entire traumatic incident was very disturbing for the child and the whole family. Everybody from the family to friends and family physicians had a different opinion on what treatment should be carried out. The treatment we provided required multiple visits but the considerable progress over time was very encouraging.

\section{Learning points}

- A multidisciplinary approach is needed to successfully treat intruded teeth.

- Revascularisation can help preserve vital pulp tissue in the apical region and the resulting thickening of the dentinal walls of the root can improve the prognosis.

- The importance of soft tissue rehabilitation is stressed for an ideal aesthetic outcome.
Figure 8 Post-operative radiographs at $3,6,9$ and 12 months showing apical closure and thickening of the dentinal walls.

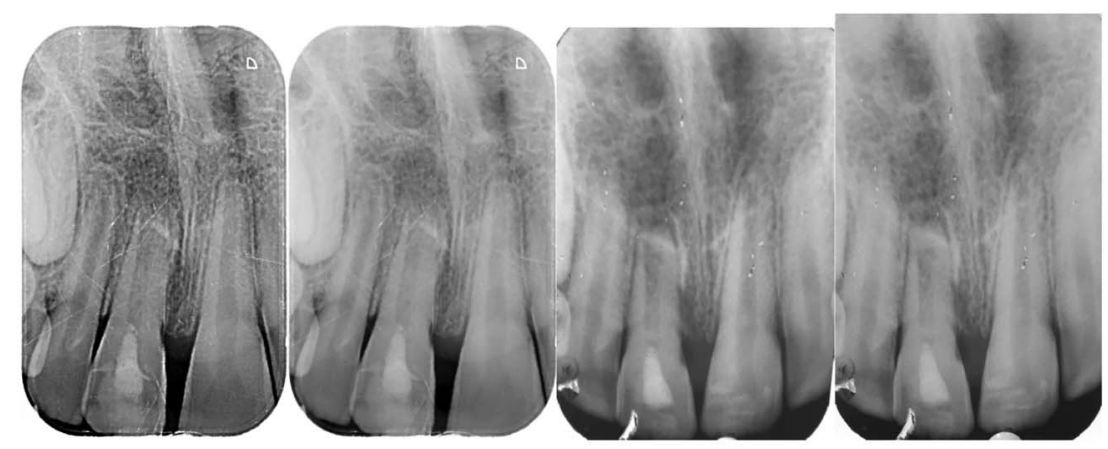

Rai P, et al. BMJ Case Rep 2016. doi:10.1136/bcr-2014-208571 
Contributors RKP and RK assisting in treatment planning. RKP supervised the endodontic revascularisation procedure. RK assisted with the periodontal procedures.

Competing interests None declared.

Patient consent Obtained.

Provenance and peer review Not commissioned; externally peer reviewed.

\section{REFERENCES}

1 Snawder K. Traumatic injuries to teeth of children. J Prev Dent 1976;3:13-20.

2 Andreasen JO, Bakland LK, Andreasen FM. Traumatic intrusion of permanent teeth. Part 2. A clinical study of the effect of preinjury and injury factors, such as sex, age, stage of root development, tooth location, and extent of injury including number of intruded teeth on 140 intruded permanent teeth. Dent Traumatol 2006;22:90-8.

3 Andreasen FM, Vestergaard-Pedersen B. Prognosis of luxated permanent teeth - the development of pulp necrosis. Endod Dent Traumatol 1985;1:207-20.

4 Tronstad L, Trope M, Bank M, et al. Surgical access for endodontic of intruded teeth. Endod Den Traumatol 1986:2:75-8.

5 Bruszt P. Secondary eruption of teeth introduced intro the maxilla by a blow. Oral Surg Oral Med Oral Pathol 1958;11:146-9.

6 Albadri S, Zaitoun H, Kinirons MJ. Treatment of traumatically intruded permanent incisor teeth in children. BSPD reviewed guidelines. Royal College Of Surgeons Of England. Intrusion Guidelines Review / /August 09/ Final/V2.

7 Araújo MAM, Valera MC. Tratamento clínico dos traumatismos dentários. São Paulo: Artes Médicas, 1999.

8 Marcos, Adriana MBLR, Regina KPL, et al. Endodontic and Orthodontic Management of Traumatically Intruded Teeth with Horizontal Root Fracture: A Case Report. Case Rep Dent 2011;2011:250267.

9 Calasans-Maia JA, Calasans-Maia MD, Matta ENR, et al. Orthodontic movement in traumatically intruded teeth: a case report. Dent Traumatol 2003;19:292-5.

10 Chaushu S, Shapira J, Heling I, et al. Emergency orthodontic treatment after the traumatic intrusive luxation of maxillary incisors. Am J Orthod Dentofacial Orthop 2004;126:162-72.

11 Chan AWK, Cheung GSP, Ho MWM. Different treatment outcomes of two intruded permanent incisors - a case report. Dent Traumatol 2001;17:275-80.

12 Andreasen FM. Pulpal healing after luxation injuries and root fracture in the permanent dentition. Endod Dent Traumatol 1989;5:111-31.

13 Iwaya SI, Ikawa M, Kubota M. Revascularization of an immature permanent tooth with apical periodontitis and sinus tract. Dent Traumatol 2001;17:185-7.

14 Banchs F, Trope M. Revascularization of immature permanent teeth with apical periodontitis: New treatment protocol? J Endod 2004;30:196-200.

15 Chueh LH, Huang GT. Immature teeth with periradicular perodontitis or abscess undergoing apexogenesis: a paradigm shift. J Endod 2006;32:1205-13.

16 Thibodeau B. Case report: pulp revascularization of a necrotic, infected, immature, permanent tooth. Pediatr Dent 2009;31:145-8.

17 Ding RY, Cheung GS, Chen J, et al. Pulp revascularization of immature teeth with apical periodontitis: a clinical study. J Endod 2009:35:745-9.

18 Gonçalves SB, Dong Z, Bramante CM, et al. Tooth slice-based models for the study of human dental pulp angiogenesis. J Endod 2007;33:811-14.
19 Shah N, Logani A, Bhaskar U, et al. Efficacy of revascularization to induce apexification/apexogenesis in infected, non vital, immature teeth: a pilot clinical study. J Endod 2008;34:919-25; Discussion 1157

20 Jung IY, Lee SJ, Hargreaves KM. Biologically based treatment of immature permanent teeth with pulpal necrosis: a case series. J Endod 2008;34:876-87.

21 Chueh $\mathrm{LH}$, Ho YC, Kuo TC, et al. Regenerative endodontic treatment for necrotic immature permanent teeth. J Endod 2009;35:160-4.

22 Nosrat A, Seifi A, Asgary S. Regenerative endodontic treatment (revascularization) for necrotic immature permanent molars: a review and report of two cases with a new biomaterial. J Endod 2011;37:562-7.

23 Iwaya S, Ikawa M, Kubota M. Revascularization of an immature permanent tooth with periradicular abscess after luxation. Dent Traumatol 2011;27:55-8.

$24 \mathrm{Kim} \mathrm{JH}, \mathrm{Kim}$ Y, Shin SJ, et al. Tooth discoloration of immature permanent incisor associated with triple antibiotic therapy: a case report. J Endod 2010;36:1086-91.

25 Zuong XY, Yang YP, Chen WX, et al. Pulp revascularization of immature anterior teeth with apical periodontitis. Hua Xi Kou Qiang Yi Xue Za Zhi 2010;28:672-4

26 Cantekin K, Herdem G, Peduk K. Revascularization in an immature necrotic permanent incisor after severe intrusive luxation injury: a case report. Eur J Paediatr Dent 2014;15(2 Suppl):203-6.

27 Wang $X$, Thibodeau B, Trope $M$, et al. Histologic characterization of regenerated tissues in canal space after the revitalization/revascularization procedure of immature dog teeth with apical periodontitis. J Endod 2010;36:56-63.

28 Mesaros SV, Trope M. Revascularization of traumatized teeth assessed by laser Doppler flowmetry: case report. Endod Dent Traumatol 1997;13:24-30.

29 Yamauchi N, Yamauchi S, Nagaoka $\mathrm{H}$, et al. Tissue engineering strategies for immature teeth with apical periodontitis. J Endod 2011;37:390-7.

30 Torabinejad M, Faras $\mathrm{H}$. A clinical and histological report of a tooth with an open apex treated with regenerative endodontics using platelet-rich plasma. J Endod 2012;38:864-8

31 Shimizu E, Jong G, Partridge $N$, et al. Histologic observation of a human immature permanent tooth with irreversible pulpitis after revascularization/regeneration procedure. J Endod 2012;38:1293-7.

32 Chen MY, Chen KL, Chen CA, et al. Responses of immature permanent teeth with infected necrotic pulp tissue and apical periodontitis/abscess to revascularization procedures. Int Endod J 2012;45:294-305.

33 Sonoyama W, Liu Y, Yamaza T, et al. Characterization of the apical papilla and its residing stem cells from human immature permanent teeth: a pilot study. J Endod 2008;34:166-71.

34 Zeichner-David M, Oishi K, Su Z, et al. Role of Hertwig's epithelial root sheath cells in tooth root development. Development Dynamics 2003;228:651-63.

35 Nanci A. Ten Cate's oral biology. 7th edn. St. Louis: Mosby, 2008.

36 Lang NP, Löe $\mathrm{H}$. The relationship between the width of keratinized gingiva and gingival health. J Periodontol 1972;43:623-7.

37 Vanarsdall RL, Corn H. Soft-tissue management of labially positioned unerupted teeth. Am J Orthod 1977;72:53-64.

38 Kermanshah $\mathrm{H}$, Ahmadi $\mathrm{E}$, Alaghehmand $\mathrm{H}$, et al. An alternative treatment of discolored non-vital endodontically treated teeth with internal resorption. $D J H$ 2012:4.

Copyright 2016 BMJ Publishing Group. All rights reserved. For permission to reuse any of this content visit http://group.bmj.com/group/rights-licensing/permissions.

BMJ Case Report Fellows may re-use this article for personal use and teaching without any further permission.

Become a Fellow of BMJ Case Reports today and you can:

- Submit as many cases as you like

- Enjoy fast sympathetic peer review and rapid publication of accepted articles

- Access all the published articles

- Re-use any of the published material for personal use and teaching without further permission

For information on Institutional Fellowships contact consortiasales@bmjgroup.com

Visit casereports.bmj.com for more articles like this and to become a Fellow 